\title{
Signaling Pathways Linked to Serotonin-Induced Superoxide Anion Production: A Physiological Role for Mitochondria in Pulmonary Arteries
}

\author{
Nafiisha Genet 1,2, Marie Billaud ${ }^{3}$, Rodrigue Rossignol ${ }^{4}$, Mathilde Dubois ${ }^{1,2}$, \\ Jennifer Gillibert-Duplantier ${ }^{1,2}$, Brant E. Isakson ${ }^{3}$, Roger Marthan ${ }^{1,2}$, \\ Jean-Pierre Savineau ${ }^{1,2}$ and Christelle Guibert ${ }^{1,2 *}$
}

${ }^{1}$ Centre de Recherche Cardio-Thoracique de Bordeaux, Institut National de la Santé et de la Recherche Médicale (INSERM), U1045, Bordeaux, France, ${ }^{2}$ Centre de Recherche Cardio-Thoracique de Bordeaux, Université de Bordeaux, Bordeaux, France, ${ }^{3}$ Robert M. Berne Cardiovascular Research Center, Charlottesville, VA, USA, ${ }^{4}$ Maladies Rares: Génétique et Métabolisme, Université de Bordeaux, Bordeaux, France

Serotonin $(5-\mathrm{HT})$ is a potent vasoconstrictor agonist and contributes to several vascular diseases including systemic or pulmonary hypertension and atherosclerosis. Although superoxide anion $\left(\mathrm{O}_{2}{ }^{-}\right)$is commonly associated to cellular damages due to $\mathrm{O}_{2} \bullet$ overproduction, we previously demonstrated that, in physiological conditions, $\mathrm{O}_{2}-$ also participates to the 5-HT contraction in intrapulmonary arteries (IPA). Here, we focused on the signaling pathways leading to $\mathrm{O}_{2}-$ production in response to $5-\mathrm{HT}$ in rat IPA. Using electron paramagnetic resonance on rat IPA, we showed that 5 - $\mathrm{HT}(100 \mu \mathrm{M})$-induced $\mathrm{O}_{2}-$ production was inhibited by ketanserin $(1 \mu \mathrm{M}-$ an inhibitor of the $5-\mathrm{HT}_{2}$ receptor), absence of extracellular calcium, two blockers of voltage-independent calcium permeable channels (RHC80267 $50 \mu \mathrm{M}$ and LOE-908 $10 \mu \mathrm{M}$ ) and a blocker of the mitochondrial complex I (rotenone-100 nM). Depletion of calcium from the sarcoplasmic reticulum or nicardipine (1 $\mu \mathrm{M}$-an inhibitor of the L-type voltage-dependent calcium channel) had no effect on the $5-\mathrm{HT}$-induced $\mathrm{O}_{2} \bullet$ production. $\mathrm{O}_{2}-$ levels were also increased by $\alpha$-methyl-5-HT (10 $\mu \mathrm{M}-$ a $5-\mathrm{HT}_{2}$ receptors agonist) whereas GR127935 (1 $\mu \mathrm{M}$-an antagonist of the 5-HT 1B/D receptor) and citalopram ( $1 \mu \mathrm{M}-\mathrm{a} 5-\mathrm{HT}$ transporter inhibitor) had no effect on the $5-\mathrm{HT}$-induced $\mathrm{O}_{2} \bullet$ production. Peroxynitrites were increased in response to $5-\mathrm{HT}(100 \mu \mathrm{M})$. In isolated pulmonary arterial smooth muscle cells loaded with rhod-2 or mitosox probes, we respectively showed that $5-\mathrm{HT}$ increased both mitochondrial calcium and $\mathrm{O}_{2}-$ levels, which were both abrogated in absence of extracellular calcium. Mitochondrial $\mathrm{O}_{2} \bullet$ levels were also abolished in the presence of rotenone $(100 \mathrm{nM})$. In pulmonary arterial smooth muscle cells loaded with TMRM, we showed that $5-\mathrm{HT}$ transiently depolarized the mitochondrial membrane whereas in the absence of extracellular calcium the mitochondrial membrane depolarisation was delayed and sustained in response to 5-HT. 5-HT decreased the mitochondrial respiratory rate measured with a Clark oxygen electrode. Altogether, in physiological conditions, $5-\mathrm{HT}$ acts on $5-\mathrm{HT}_{2}$ receptors and induces an $\mathrm{O}_{2}-$ production dependent on extracellular calcium and mitochondria.

Keywords: superoxide anion, 5-HT, mitochondria, pulmonary artery, calcium 


\section{INTRODUCTION}

Several agonists acting on seven transmembrane domain receptors (G-protein coupled receptors) are involved in vascular tone. Serotonin (5-HT) is a potent vasoconstrictor agonist under physiological conditions and contributes to several vascular diseases (namely systemic or pulmonary hypertension and atherosclerosis). In the lung, 5-HT is locally released by pulmonary neuroendocrine cells, endothelial cells and neuroepithelial bodies distributed throughout the airways (Maclean and Dempsie, 2010). In the cardiovascular system, 5-HT has a potent mitogenic and contractile effect and its concentration is increased in pulmonary hypertension (Kéreveur et al., 2000; Guibert et al., 2004; Rodat et al., 2007; Rodat-Despoix et al., 2008). The mitogenic effect of 5-HT in the pulmonary artery (PA) is dependent on 5-HT uptake through the 5-HT transporter (Maclean and Dempsie, 2010) and the activation of 5$\mathrm{HT}$ receptors whereas the contractile effect of 5- $\mathrm{HT}$ is mainly due to its action on $5-\mathrm{HT}_{2 \mathrm{~A}}$ and $5-\mathrm{HT}_{1 \mathrm{~B} / \mathrm{D}}$ receptors (Rodat-Despoix et al., 2008).

We previously demonstrated, in rat intrapulmonary arteries (IPA), that 5-HT increases superoxide anion $\left(\mathrm{O}_{2} \bullet\right.$ - levels in smooth muscle and such $\mathrm{O}_{2} \bullet$ participates to pulmonary vasoconstriction (Billaud et al., 2009). Nevertheless, so far, no studies have yet elucidated the signaling pathways that are triggered in this process.

$5-\mathrm{HT}$ is also well-known to stimulate reactive oxygen species (ROS) production in human, bovine, and mice pulmonary artery smooth muscle cells (PASMC) and the production of $\mathrm{O}_{2}-$ facilitates 5-HT-induced pulmonary vasoconstriction as well as smooth muscle cells proliferation (Lee et al., 1998, 1999, 2001; Liu and Folz, 2004; Lawrie et al., 2005; Peña-Silva et al., 2009). While the role of ROS in 5-HT-induced PASMC proliferation has been extensively studied, only one study, on mouse PA, addressed the role of ROS in 5-HT-induced contraction (Liu and Folz, 2004). Indeed, Liu and Folz showed that 5 -HT enhances $\mathrm{O}_{2} \bullet$ levels via NADPH oxidase stimulation in the smooth muscle (Liu and Folz, 2004). This increased $\mathrm{O}_{2} \bullet$ was localized in the extracellular space and further increased the contraction to 5-HT. However, so far, the precise mechanisms involved in the enhanced 5-HTinduced contraction by $\mathrm{O}_{2} \bullet$ in mice PA have not been addressed to date and the exact role of $5-\mathrm{HT}_{2}$ receptors, $5-\mathrm{HT}$ transporter and mitochondria (another important source of $\mathrm{O}_{2} \bullet$ ) still remain unknown (Cogolludo et al., 2006; Perez-Vizcaino et al., 2010).

In human as in rats, PA contraction to $5-\mathrm{HT}$ is dependent on myofilament $\mathrm{Ca}^{2+}$-sensitization and cytosolic calcium concentration (Guibert et al., 2004; Rodat-Despoix et al., 2008, 2009). Intracellular calcium level is modulated by the activity of calcium permeable channels localized at the plasma membrane and in the sarcoplasmic reticulum. Upon binding to its $5-\mathrm{HT}_{2}$ receptors, 5-HT induces a rise in cytosolic calcium coming from both (i) the intracellular compartment, mainly the sarcoplasmic

Abbreviations: 5-HT, serotonin; EPR, electron paramagnetic resonance; IPA, intrapulmonary artery; KHB, Krebs-Hepes-Bicarbonate; METC, mitochondrial electron transport chain; $\mathrm{O}_{2} \bullet$, superoxide anion; $\mathrm{ONOO}^{-}$, peroxynitrite; $\mathrm{PA}$, pulmonary artery; PASMC, pulmonary artery smooth muscle cells; ROS, reactive oxygen species; SOD, superoxide dismutase. reticulum, and (ii) an influx of extracellular calcium (Guibert et al., 2004). In pulmonary arterial smooth muscle, calcium influx is due to the activation of voltage-dependent calcium channels and voltage-independent calcium channels (Guibert et al., 2004; Ducret et al., 2008; Rodat-Despoix et al., 2008). However, we have previously shown, in rat IPA, that both the contraction and the calcium response to 5-HT are strongly dependent on voltageindependent calcium channels compared to voltage-dependent calcium channels (Guibert et al., 2004; Rodat et al., 2007; RodatDespoix et al., 2008).

Altogether, since the mitochondrial electron transport chain (METC) is known to be sensitive to calcium to produce $\mathrm{O}_{2} \bullet$ (Denton et al., 1978; Archer et al., 1993; Yuan et al., 1993; Leach et al., 2001; Dromparis and Michelakis, 2013; Freund-Michel et al., 2014; Yumnam et al., 2016) we have investigated, in the present study, the signaling pathways involved in 5-HT-induced $\mathrm{O}_{2} \bullet$ increase in rat IPA by focusing on the mitochondria as an important source of ROS and the role of intra and extracellular calcium.

\section{MATERIALS AND METHODS}

\section{Tissue Preparation}

Male Wistar rats (weighing 300-400 g) were sacrificed using an intraperitoneal injection of pentobarbital $(150 \mathrm{mg} / \mathrm{kg})$ according to the animal care and use local committee (Comité d'éthique régional d'Aquitaine). All the experiments were carried out in accordance with the recommendations of the Comité d'éthique régional d'Aquitaine (CEEA 50) and the protocol was approved by the same committee (protocol $\mathrm{n}^{\circ}$ 50110016A). The left lung was rapidly removed and rinsed in KrebsHEPES-bicarbonate (KHB) containing (in $\mathrm{mM}$ ): $118.4 \mathrm{NaCl}, 4.7$ $\mathrm{KCl}, 1.2 \mathrm{MgSO}_{4}, 4 \mathrm{NaHCO}_{3}, 1.2 \mathrm{KH}_{2} \mathrm{PO}_{4}, 2 \mathrm{CaCl}_{2}, 10 \mathrm{~N}-2-$ hydroxyethylpiperazine-N'-2-ethanesulfonic acid (HEPES) and 6 D-glucose, $\mathrm{pH} 7.4$ with $\mathrm{NaOH}$. Intrapulmonary arteries (IPA) of first, second and third order with an external diameter ranging from $300 \mu \mathrm{m}$ to $2 \mathrm{~mm}$ were then dissected free from surrounding connective tissues under binocular control.

\section{Electronic Paramagnetic Resonance (EPR) Recordings}

EPR recordings were performed as previously described (Billaud et al., 2009). IPA were incubated in the spin trap solution containing $500 \mu \mathrm{M} \quad$ 1-hydroxy-3-methoxycarbonyl-2,2,5,5tetramethylpyrrolidin ( $\mathrm{CMH}$, Noxygen), $25 \mu \mathrm{M}$ deferoxamine (Sigma), and $5 \mathrm{mM} \mathrm{N}, \mathrm{N}$-diethyldithiocarbamate (DETC, Sigma) in $\mathrm{KHB}$ at $37^{\circ} \mathrm{C}$ for $45 \mathrm{~min}$. 5-HT was added during the spin trap incubation. When indicated, pharmacological inhibitors were also added $30 \mathrm{~min}$ prior and during the spin trap incubation. The reaction was stopped by snap freezing the samples in liquid nitrogen. Samples were then analyzed by EPR spectrometry using a tabletop X-band spectrometer miniscope (MS200, Magnettech). Spectra of the oxidized product of $\mathrm{CMH}\left(\mathrm{CM}^{\bullet}\right)$ were recorded at $77^{\circ} \mathrm{K}$ using a flask Dewar. Acquisition parameters were as followed: Bo Field: $3341 \pm 150 \mathrm{G}$, microwave power: $10 \mathrm{~dB}$, amplitude modulation: 5 G, sweep time: 60 s, gain: 300 and 3 scans. Signals were 
quantified by measuring the total amplitude of the signal, after correction of baseline and normalized to the protein quantity of the sample in $\mathrm{mg} / \mathrm{ml} . \mathrm{O}_{2} \bullet$ level was expressed as $[\mathrm{A} /(\mathrm{mg} / \mathrm{ml})$ of proteins $]$, where A corresponds to arbitrary units.

\section{Quantification of Peroxynitrites}

IPA were incubated with or without 5-HT $100 \mu \mathrm{M}$ in phosphate buffer saline solution during $45 \mathrm{~min}$. Arteries were then homogenized in this incubation medium and centrifuged $\left(10500 \mathrm{~g}, 20 \mathrm{~min}\right.$ at $\left.4^{\circ} \mathrm{C}\right)$. Supernatants were further used for the measurement of peroxynitrites. As peroxynitrites are rapidly transformed to their more stable structural isomer, nitrates, supernatants were first incubated with nitrate reductase (Cayman chemicals) to convert nitrates into nitrites. Levels of peroxynitrites were then quantified from nitrites with Griess reagent according to the manufacturer's instructions (Molecular probes). Peroxynitrites levels were normalized to tissue protein content in $\mathrm{mg} / \mathrm{ml}$. Results are expressed as $[(\mu \mathrm{M}) /(\mathrm{mg} / \mathrm{ml})$ of proteins].

\section{Measurement of Superoxide Dismutase (SOD) Activity}

IPA treated or not with 5-HT were homogenized in HEPES buffer containing (in $\mathrm{mM}$ ): 20 HEPES, 1 EGTA, 210 mannitol, 70 sucrose, pH 7.2 with $\mathrm{NaOH}$. Homogenized samples were centrifuged ( $1500 \mathrm{~g}, 5 \mathrm{~min}$ at $4^{\circ} \mathrm{C}$ ) and supernatants were used for the determination of superoxide dismutase (SOD) activity. SOD enzyme activity was then determined as described in the procedure of the SOD Assay Kit-WST from Sigma and as carried out in previous studies (Peskin and Winterbourn, 2000). Briefly, the method is based on the inhibition of the SOD activity in presence of the highly water-soluble tetrazolium salt WST-1 [2-(4-Iodophenyl)-3-(4-nitrophenyl)5-(2,4-disulfophenyl)-2H-tetrazolium, monosodium salt] that produces a colored water-soluble formazan dye (WST1formazan) upon reduction with $\mathrm{O}_{2} \bullet$. Levels of SOD activity were determined by measuring the absorbance of the WST1formazan dye at $450 \mathrm{~nm}$ with a microplate reader (EL808, Bio-Tek instruments). SOD standard solutions ranging from 0.001 to 200 Units $/ \mathrm{ml}$ were used to perform a calibration curve and SOD activity value was read from this curve and expressed as Units/ml for each sample. Tissue protein content of each sample was also quantified in $\mathrm{mg} / \mathrm{ml}$ to normalize SOD enzyme activity, expressed as Units/mg of proteins.

\section{Quantification of Total Protein Levels}

Briefly, IPA were lysed in RIPA buffer (Sigma) for total protein extraction. The lysed tissues were centrifuged at 15,000 $\mathrm{g}$ for 10 $\min$ at $4^{\circ} \mathrm{C}$. The amount of total protein in the supernatant was measured using a lowry assay (Biorad DC protein assay) following the manufacturer's instructions. The amount of protein in each sample was compared to a standard curve performed with bovine serum albumin (BSA, $0-2 \mathrm{mg} / \mathrm{ml}$ ).

\section{Pulmonary Arterial Smooth Muscle Cells Culture}

PASMC were obtained as previously described (Martin et al., 2012). Briefly, IPA from the rat left lung were dissected free from surrounding connective tissues. IPA were cut into small pieces and placed in Hanks Balanced Salt Solution containing $50 \mu \mathrm{M} \mathrm{CaCl}, 0.5 \mathrm{mg} / \mathrm{ml}$ papain, $0.3 \mathrm{mM}$ dithioerythritol, and $0.3 \mathrm{mg} / \mathrm{ml}$ collagenase for $10 \mathrm{~min}$ at $37^{\circ} \mathrm{C}$. IPA were then mechanically and gently agitated using a polished wide-bore Pasteur pipette to release the cells. PASMC were seeded onto $14 \mathrm{~mm}$ round glass coverslips, maintained in culture medium (DMEM) supplemented with $1 \%$ penicillin- streptomycin, $1 \%$ sodium pyruvate, $1 \%$ non essential amino acids, and $10 \%$ fetal calf serum. Cells were stored at $37^{\circ} \mathrm{C}$ in a humidified atmosphere gassed with $5 \% \mathrm{CO}_{2}$. When the PASMC reached $80 \%$ confluence, they were growth arrested by using serumfree culture medium supplemented with $1 \%$ insulin-transferrinselenium. After $48 \mathrm{~h}$, recordings of cytosolic and mitochondrial calcium, mitochondrial membrane potential, and mitochondrial $\mathrm{O}_{2} \bullet$ measurements with fluorescent dyes were performed. For mitochondrial respiration assessment, PASMC were seeded in $175-\mathrm{cm}^{2}$ flasks and grown until confluence. Cells were used up to passage 4. PASMC phenotype was confirmed by positive immunostaining for $\alpha$-smooth muscle actin and calponin.

\section{Measurements of Mitochondrial Respiration}

Endogenous cellular oxygen consumption was monitored on a suspension of $\mathrm{PASMC}$ at $37^{\circ} \mathrm{C}$ in a $1 \mathrm{ml}$ thermostatically controlled chamber $\left(1.0 \times 10^{6}\right.$ cells $\left./ \mathrm{ml} / \mathrm{run}\right)$ equipped with a Clark oxygen electrode (Oxygraph system, Hansatech) as previously described (Rossignol et al., 2004). The respiratory buffer was the DMEM growth medium without serum. Cumulative concentrations of 5-HT were added to the chamber when indicated. The basal respiratory rate is expressed as nmol $\mathrm{O}_{2} / \mathrm{min} / 10^{6}$ cells and the effect of 5 -HT was calculated as a percentage of the basal respiratory rate.

\section{Recording of Cytosolic and Mitochondrial Calcium and Mitochondrial Membrane Potential}

Cytosolic and mitochondrial calcium were assessed by simultaneously loading PASMC with the non ratiometric fluo4AM probe $(2 \mu \mathrm{M})$ and rhod-2AM probe $(1 \mu \mathrm{M})$ respectively. PASMC were also loaded simultaneously with rhod-2AM $(1 \mu \mathrm{M})$ and mitotracker green (400 nM), a mitochondrial marker, for mitochondria labeling. For mitochondrial membrane potential measurements, PASMC were loaded with tetramethylrhodamine methyl ester (TMRM) $(100 \mathrm{nM})$. All the fluorescent dyes used were obtained from Molecular probes (Invitrogen). For all the above mentioned experiments, PASMC were loaded with the dyes for $30 \mathrm{~min}$ at $37^{\circ} \mathrm{C}$ in $\mathrm{KHB}$ solution and then washed in KHB solution without the dye for 30 min to allow deesterification of the dye. PASMC were then mounted on the stage of a laser scanning confocal microscope (TE2000, Nikon, Champigny-Sur-Marne, France) with a x 20, 1.40 NA 
plan apochromat oil-immersion objective. The cells were under continuous bath perfusion with $\mathrm{KHB}$ solution at a rate of 2 $\mathrm{ml} / \mathrm{min}$ and 5 -HT $100 \mu \mathrm{M}$ was bath-applied. Fluo-4AM was excited with an argon laser at $488 \mathrm{~nm}$ and emitted light was filtered at $515 \pm 30 \mathrm{~nm}$. Rhod-2AM and TMRM were excited with a helium-neon laser at $543 \mathrm{~nm}$ and the emitted light was filtered at $605 \pm 75 \mathrm{~nm}$. Regions of interest were drawn around each cell and fluorescence was recorded every $2 \mathrm{~s}$ by using the EZ-C1 software (Nikon, Champigny-Sur-Marne, France). All experiments were performed at room temperature. The fluorescence values $(F)$ were normalized to the basal fluorescence (fluorescence before application of the agonists or F0) to obtain the fluorescence ratio (F/F0). The area under the curve was calculated with Origin 6.0 software (Microcal). The area under the curve was calculated for a $75 \mathrm{~s}$ duration, starting $45 \mathrm{~s}$ after the beginning of the recording, which corresponds to the time where the agonist was applied. Results are expressed as (F/F0)s ${ }^{-1}$.

\section{Measurement of Mitochondrial $\mathrm{O}_{2}-$ Production}

Mitochondrial $\mathrm{O}_{2} \bullet$ production was measured with mitoSox red (molecular probes). PASMC were loaded with mitoSox red $(4 \mu \mathrm{M})$ in $\mathrm{KHB}$ for $20 \mathrm{~min}$ at $37^{\circ} \mathrm{C}$. PASMC were washed twice and mounted on the stage of a laser scanning confocal microscope (TE2000, Nikon, Champigny-Sur-Marne, France) with a $\mathrm{x} 20,1.40 \mathrm{NA}$ plan apochromat oil-immersion objective. 5 -HT $(100 \mu \mathrm{M})$ was applied at $t=0 \mathrm{~min}$. MitoSox red was excited with an helium-neon laser at $543 \mathrm{~nm}$ and the emitted light was filtered at $605 \pm 75 \mathrm{~nm}$. Regions of interest were drawn around each cell and fluorescence was recorded every $15 \mathrm{~min}$ for $60 \mathrm{~min}$ by using the EZ-C1 software (Nikon, Champigny-Sur-Marne, France). The fluorescence values at the start of the experiment (F0) were subtracted from the fluorescence at $t=60 \mathrm{~min}(\mathrm{~F})$ to calculate the percentage of increase in mitoSox red fluorescence.

\section{Drugs and Chemical Reagents}

All drugs were diluted in distilled water, except for LOE-908, nicardipine, RHC-80267, and rotenone, which were dissolved in dimethyl sulphoxide (DMSO). Antimycin A was dissolved in ethanol. The maximal concentration of DMSO and ethanol used in experiments was $<0.1 \%$.

\section{Data Analysis and Statistics}

All results are expressed as mean \pm SEM; $n$ indicates the number of rats for EPR, peroxynitrites measurements, SOD activity and mitochondrial respiratory rate, the number of cells for cytosolic, mitochondrial calcium, mitochondrial membrane potential, and mitochondrial superoxide anion recordings. Experiments were performed on a minimum of 3-4 rats. Unpaired $t$-test was used to compare data obtained from measurements of cytosolic, mitochondrial calcium levels, and mitochondrial membrane potential. Non-parametric one way ANOVA (Kruskal-Wallis) followed by Dunn's multiple comparison tests was used to compare mitochondrial respiration. All other data were analyzed using a non-parametric test for unpaired samples (MannWhitney test). All bar graphs and statistics were performed with GraphPad Prism 5. Values of $P<0.05$ were considered significant.

\section{RESULTS}

\section{5-HT-Induced Production of $\mathrm{O}_{2}{ }^{-}$in Rat IPA}

We previously demonstrated that 5-HT had a maximal contractile effect at the concentration of $100 \mu \mathrm{M}$ in rat IPA (Billaud et al., 2009). Moreover, the maximal effect of the anti-oxidant PEG-SOD and PEG-catalase was observed on the contraction to 5-HT $100 \mu \mathrm{M}$ (Billaud et al., 2009). Therefore, we focused our study on $\mathrm{O}_{2} \bullet$ produced by $5-\mathrm{HT} 100 \mu \mathrm{M}$. Indeed, as previously demonstrated (Billaud et al., 2009), a new set of experiments has been performed with electron paramagnetic resonance (EPR) recordings confirming that 5-HT $(100 \mu \mathrm{M})$ significantly increased $\mathrm{O}_{2} \bullet$ levels in rat IPA $(n=13$ and 12) (Figure 1A). Similarly, 5-HT $(100 \mu \mathrm{M})$ also significantly increased $\mathrm{O}_{2} \bullet$ levels in rat aorta $(n=7)$ (Figure 1B). Since $\mathrm{O}_{2} \bullet$ can be scavenged by $\mathrm{NO}$ to form peroxynitrites $\left(\mathrm{ONOO}^{-}\right)$, we measured $\mathrm{ONOO}^{-}$concentration in rat IPA with Griess reagent as an alternative means to investigate 5-HT-induced $\mathrm{O}_{2} \bullet$ increase. 5-HT significantly increased $\mathrm{ONOO}^{-}$levels (Figure 1C). Moreover, in rat IPA, 5-HT had no significant effect on the activity of superoxide dismutase, an anti-oxidant enzyme responsible for $\mathrm{O}_{2} \bullet$ degradation (Figure 1D). Altogether, 5-HT produces $\mathrm{O}_{2} \bullet$ in IPA and aorta and modification of superoxide dismutase activity cannot explain 5-HT-induced $\mathrm{O}_{2} \bullet$ increase in IPA.

\section{Role of 5-HT Receptors, 5-HT Transporter and Calcium in 5-HT-Induced $\mathrm{O}_{2}-$ Increase}

Pulmonary arterial contraction in response to $5-\mathrm{HT}$ is known to be mediated by $\mathrm{O}_{2} \bullet$, $5-\mathrm{HT}$ receptors $\left(5-\mathrm{HT}_{2 \mathrm{~A}}\right.$ and $\left.5-\mathrm{HT}_{1 \mathrm{~B} / \mathrm{D}}\right)$ and, to a lesser extent, by the 5-HT transporter (Morecroft et al., 2005; Billaud et al., 2009). We have thus used selective pharmacological inhibitors and activators to study the role of the 5-HT transporter, 5- $\mathrm{HT}_{2}$, and $5-\mathrm{HT}_{1 \mathrm{~B} / \mathrm{D}}$ receptors involved in IPA contraction. EPR recordings showed that ketanserin $(1 \mu \mathrm{M})$, a $5-\mathrm{HT}_{2}$ receptor antagonist significantly decreased the amount of $\mathrm{O}_{2} \bullet$ produced by $5-\mathrm{HT}(n=9)$ (Figure 2A) whereas blocking the $5-\mathrm{HT}_{1 \mathrm{~B} / \mathrm{D}}$ receptors or the 5 -HT transporter by GR $127935(1 \mu \mathrm{M})$ or citalopram $(1 \mu \mathrm{M})$, respectively, had no effect $(n=11-12)$ (Figure 2A). Moreover, $\alpha$-methyl 5-HT $(10 \mu \mathrm{M})$, a non-selective $5-\mathrm{HT}_{2}$ agonist significantly increased $\mathrm{O}_{2} \bullet$ levels $(n=6)$ (Figure 2B).

Given the importance of calcium in the contraction to 5-HT in rat IPA, we have then studied the role of intracellular calcium by depleting the calcium from the sarcoplasmic reticulum with a calcium free KHB solution containing a calcium chelator (0.4 mM EGTA), an activator of ryanodine receptors (caffeine $5 \mathrm{mM}$ ) and an inhibitor of the sarcoplasmic reticulum $\mathrm{Ca}^{2+}$ ATPase (thapsigargin $1 \mu \mathrm{M}$ ) to prevent calcium re-uptake in the sarcoplasmic reticulum. Such protocol has been shown to fully deplete sarcoplasmic reticulum in calcium in rat pulmonary arteries (Gonzalez De La Fuente et al., 1995; Guibert et al., 1996). Once the sarcoplasmic reticulum was depleted in calcium, extracellular calcium was reintroduced in the incubation medium 
A

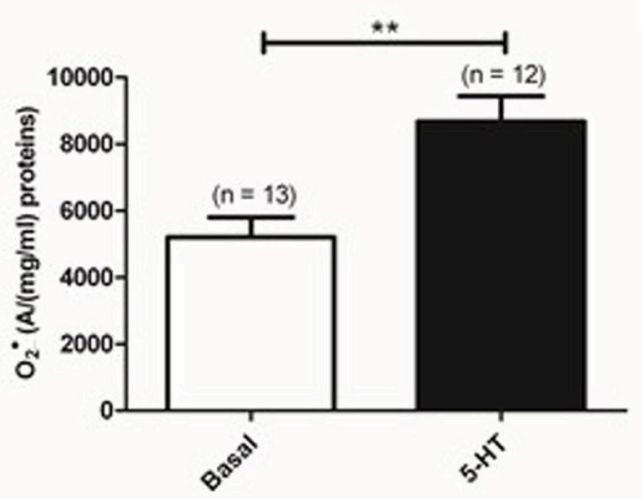

C

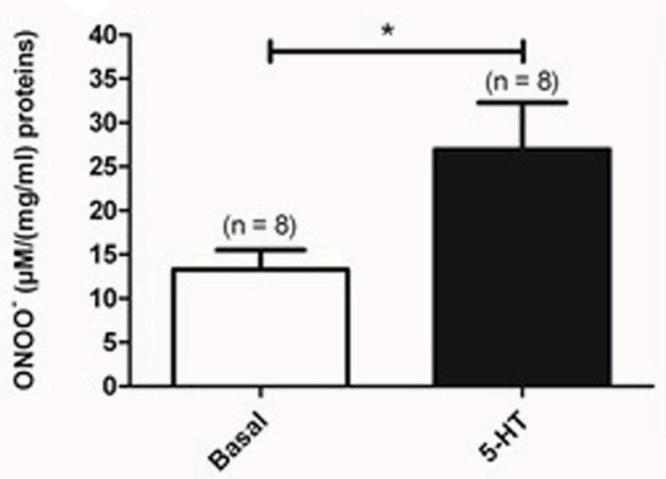

B Aorta

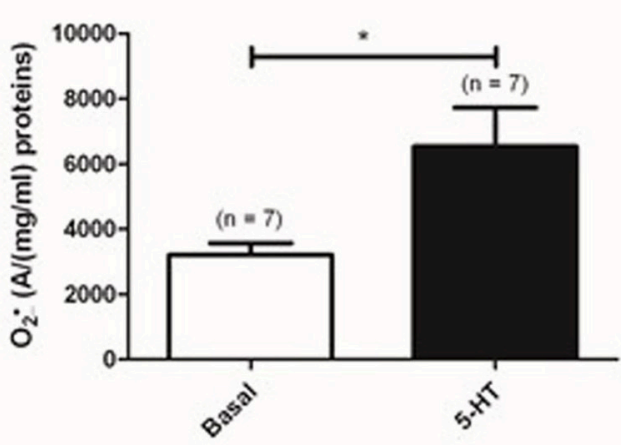

D

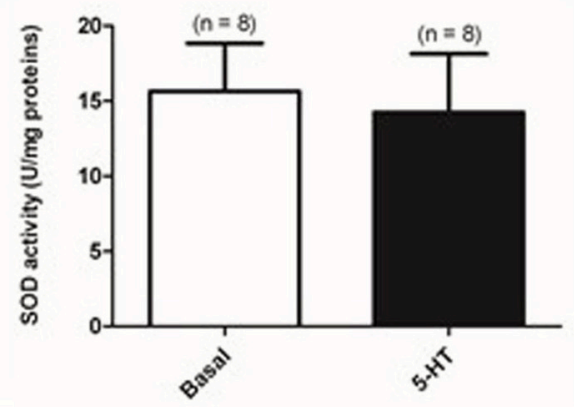

FIGURE 1 | Production of $\mathrm{O}_{2}-$ by $\mathbf{1 0 0} \mu \mathbf{M}$ 5-HT. Levels of $\mathrm{O}_{2}-$ were measured by EPR spectrometry in basal conditions (white column) or in the presence of 5 - $\mathrm{HT}$ (black column) in rat IPA (A) or aorta (B). (C) 5-HT increases ONOO- levels in rat IPA. (D) 5-HT does not modify SOD activity measured in rat IPA. Data are expressed as mean \pm SEM. ${ }^{* *}$ and ${ }^{*}$ mean a significant difference for $P<0.01$ and $P<0.05$ respectively. $\mathrm{n}$ is the number of rats.

allowing the activation of store-operated calcium permeable channels in the plasma membrane. The role of extracellular calcium was studied by incubating IPA in calcium free KHB solution containing $0.4 \mathrm{mM}$ EGTA. Unlike the absence of calcium from sarcoplasmic reticulum, absence of extracellular calcium significantly reduced 5 -HT-induced $\mathrm{O}_{2} \bullet$ increase $(n=12-13)$ (Figure 3A). Moreover, absence of both intra and extracellular calcium did not further affect 5 -HT-induced $\mathrm{O}_{2} \bullet$ production $(n=7)$ (Figure 3A).

We have then investigated the role of the voltage-dependent and voltage-independent calcium channels on 5-HT-induced $\mathrm{O}_{2} \bullet$ increase by using their respective blockers in rat IPA. Nicardipine $(1 \mu \mathrm{M})$, an L- type voltage-dependent calcium channels blocker, did not prevent $\mathrm{O}_{2} \bullet$ increase in response to 5-HT (Figure 3B). LOE-908 $(10 \mu \mathrm{M})$, a voltage-independent calcium channel inhibitor and RHC-80267 (50 $\mu \mathrm{M})$, a DAG lipase inhibitor which will prevent arachidonic acid to stimulate voltage-independent calcium channels, were then used because they were already known to decrease contraction and calcium response to 5-HT in rat IPA (Guibert et al., 2004). LOE 908 and RHC-80267 both significantly decreased 5-HT-induced
$\mathrm{O}_{2} \bullet$ increase (Figure 3C). Altogether, $5-\mathrm{HT}$ stimulation of rat IPA produced $\mathrm{O}_{2} \bullet$ via the activation of the $5-\mathrm{HT}_{2}$ receptors and a calcium influx through voltage-independent calcium channels.

\section{Role of ROS Sources in the Production of $\mathrm{O}_{2}-$ by $5-\mathrm{HT}$ in Rat IPA}

METC is known to be an important source of $\mathrm{O}_{2} \bullet$ (PerezVizcaino et al., 2010). Using EPR recordings in rat IPA, we showed that rotenone $(100 \mathrm{nM})$, an inhibitor of the complex I of the METC significantly decreased the amount of $\mathrm{O}_{2} \bullet$ produced by 5 -HT $(100 \mu \mathrm{M})$ (Figure $4 \mathrm{~A})$. However, antimycin A $(10 \mu \mathrm{M})$, a complex III cytochrome $b_{\mathrm{H}}$ inhibitor did not exhibit any significant effect on 5 -HT-induced $\mathrm{O}_{2} \bullet$ production in rat IPA (Figure 4A). Rotenone did not modify basal $\mathrm{O}_{2} \bullet$ level ( $n=6$-data not shown). To confirm the role of mitochondria, we addressed the effect of 5-HT on the mitochondrial respiratory rate and on the mitochondrial membrane potential. 5-HT significantly decreased the mitochondrial respiratory rate (Figure 4B). The mitochondrial membrane was transiently depolarized in response to $5-\mathrm{HT} 100 \mu \mathrm{M}$ in the presence 


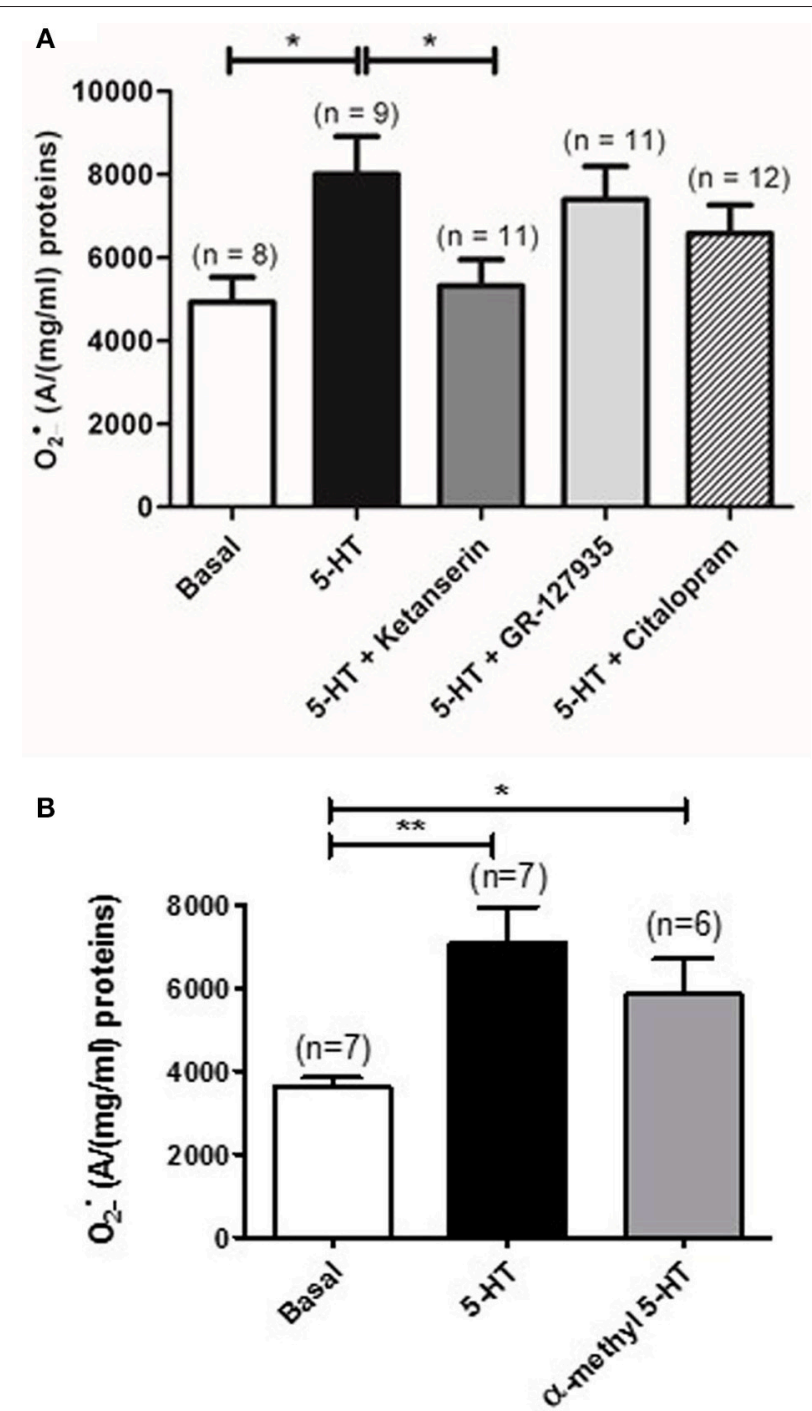

FIGURE 2 | Role of 5-HT receptors and 5-HT transporter in 5-HT-induced $\mathrm{O}_{2}-$ increase in rat IPA. (A) Effect of a $5-\mathrm{HT}_{2}$ receptor antagonist (ketanserin, $1 \mu \mathrm{M}$, dark gray column), a 5- $\mathrm{HT}_{1}$ receptor antagonist (GR127935, $1 \mu \mathrm{M}$, light gray column) or a 5-HT transporter antagonist (citalopram, $1 \mu \mathrm{M}$, hatched column) on the $\mathrm{O}_{2} \bullet$ produced by $100 \mu \mathrm{M} 5-\mathrm{HT}$. (B) $\alpha$-methyl $5-\mathrm{HT} 10 \mu \mathrm{M}$ significantly increases $\mathrm{O}_{2}$ - levels in rat IPA. Data are expressed as mean \pm SEM. * and ** indicate a significant difference with $P<0.05$ and $P<0.01$ respectively. $\mathrm{n}$ is the number of rats.

of extracellular calcium (Figures 5A,B) whereas, in its absence, the depolarization was strongly delayed and sustained (Figures 5B,C).

Since extracellular calcium influx and mitochondria both play a key role in the production of $\mathrm{O}_{2} \bullet$ by 5 - $\mathrm{HT}$ (Figures $3 \mathrm{~A}, \mathrm{C}$, 4A), we hypothesized that calcium influx induced by 5 -HT would trigger an increase in mitochondrial calcium. We have thus simultaneously measured cytosolic and mitochondrial calcium levels in PASMC, in response to 5-HT in the presence and in the absence of extracellular calcium. Fluorescent labeling of PASMC with mitotracker green, a mitochondrial marker, and rhod-2, a mitochondrial calcium dye, shows a high level of
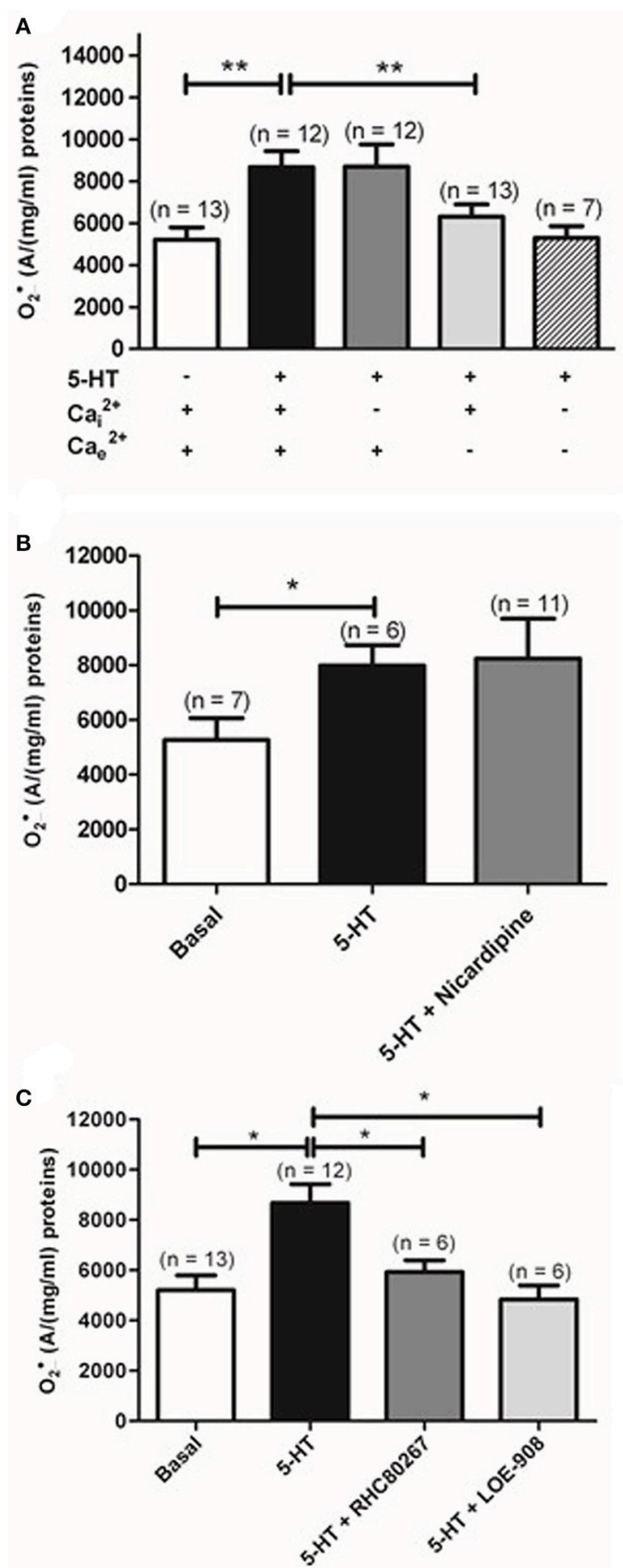

FIGURE 3 | Role of calcium and calcium permeable channels in 5-HT-induced $\mathrm{O}_{2}{ }^{-}$increase in rat IPA. (A) Effect of removal of $\mathrm{Ca}^{2+}$ from the sarcoplasmic reticulum $\left(\mathrm{Ca}_{\mathrm{i}}^{2+}\right.$, dark gray column) or extracellular $\mathrm{Ca}^{2+}$ ( $\mathrm{Ca}_{\mathrm{e}}^{2+}$, light gray column), or both $\mathrm{Ca}_{i}^{2+}$ and $\mathrm{Ca}_{\mathrm{e}}^{2+}$ (hatched column) on $\mathrm{O}_{2}-$ produced by $100 \mu \mathrm{M} 5-\mathrm{HT}$ and measured by EPR spectrometry. Effect of nicardipine $(1 \mu \mathrm{M})$, an L-type voltage-gated calcium channel inhibitor (dark gray column) or two antagonists of voltage-independent calcium permeable channel, RHC-80267 (50 $\mu \mathrm{M})$ and LOE-908 (10 $\mu \mathrm{M})$ (dark and light gray columns respectively) on the $\mathrm{O}_{2}-$ produced by $100 \mu \mathrm{M} 5-\mathrm{HT}$ (B and $\mathbf{C}$ respectively). Data are expressed as mean \pm SEM. ** and * mean a significant difference for $P<0.01$ and $P<0.05$ respectively. $\mathrm{n}$ is the number of rats. 
A

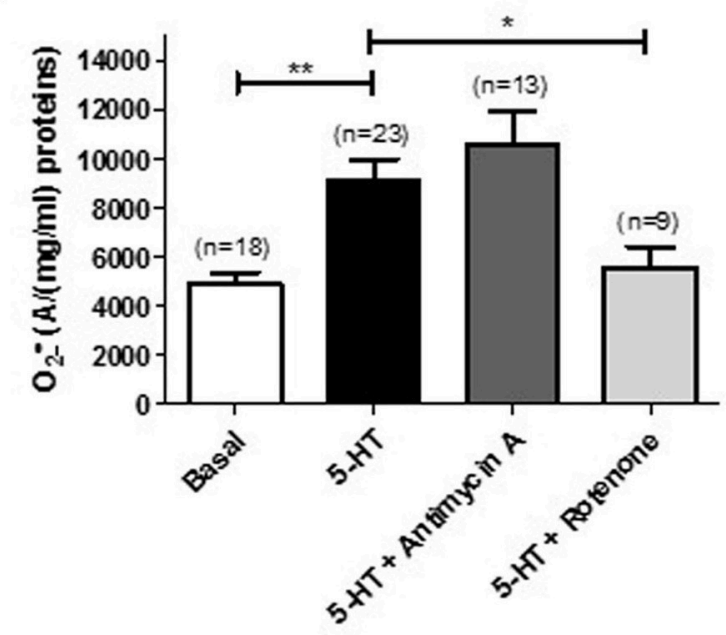

B

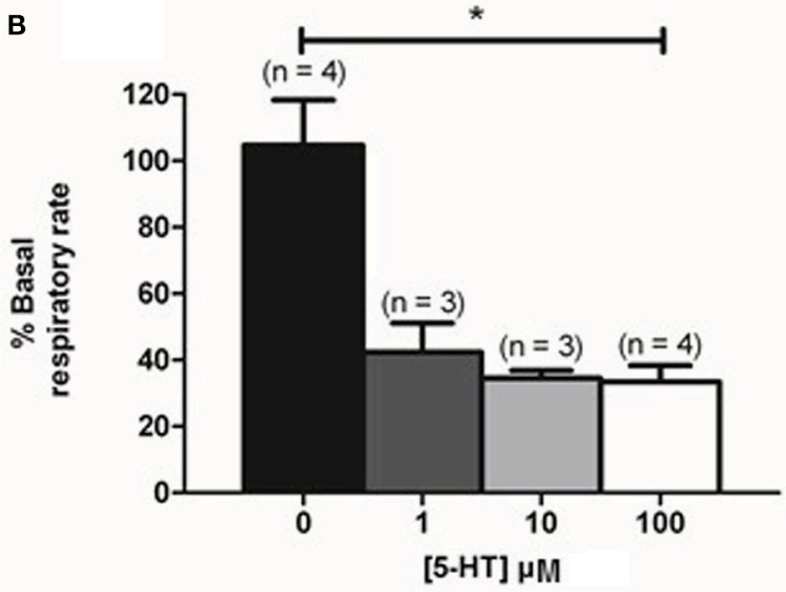

FIGURE 4 | Mitochondrial activity is modified in response to 5-HT. (A) Effect of inhibitors of the complex III and I of the mitochondrial respiratory chain (Antimycin A, $10 \mu \mathrm{M}$ and rotenone, $100 \mathrm{nM}$, dark and light gray columns respectively) is shown on the $\mathrm{O}_{2}-$ produced by $100 \mu \mathrm{M} 5-\mathrm{HT}$ in rat IPA. $\mathrm{n}$ is the number of vessels. (B) Illustrates mitochondrial activity, expressed as a \% of basal respiratory rate in response to cumulative concentrations of $5-\mathrm{HT}$ (1 to $100 \mu \mathrm{M})$ in PASMC. $\mathrm{n}$ is the number of rats. Data are expressed as

mean \pm SEM. ${ }^{*}$ and ${ }^{*}$ mean a significant difference for $P<0.01$ and $P<0.05$ respectively.

colocalization demonstrating the specific targeting of rhod-2 to the mitochondrial network (Figures 6A-C). 5-HT (100 $\mu \mathrm{M})$ increased both cytosolic and mitochondrial calcium levels in the presence of extracellular calcium (Figures 6D,F). In the absence of 5-HT stimulation, both cytosolic and mitochondrial calcium levels did not vary over time (data not shown). In the absence of extracellular calcium, the rise in cytosolic calcium in response to 5-HT was significantly decreased and the rise in mitochondrial calcium almost disappeared (Figures 6E,F). It should be noted that mitochondrial calcium increase is slightly delayed compared to cytosolic calcium increase (Figure 6D) suggesting that calcium influx may trigger the increase in mitochondrial calcium. In addition, we specifically measured mitochondrial $\mathrm{O}_{2} \bullet$ with the fluorescent probe mitosox. 5-HT $(100 \mu \mathrm{M})$ significantly increased mitochondrial $\mathrm{O}_{2}-$ levels (Figures 7Aa,Ab,B) and this $\mathrm{O}_{2} \bullet$ increase was significantly inhibited in the absence of extracellular calcium (Figures 7Ac,Ad,B) or the presence of rotenone $(100 \mathrm{nM})$ (Figure $7 \mathbf{B})$. Altogether, these results confirm the role of mitochondria, mitochondrial complex I and extracellular calcium in the signaling pathways involved in response to $5-\mathrm{HT}$ in rat IPA.

\section{DISCUSSION}

Our findings provide the first comprehensive description of the role of mitochondria and calcium in 5-HT-induced $\mathrm{O}_{2} \bullet$ increase in rat IPA. Here, we clearly show that $5-\mathrm{HT}$ acts on $5-\mathrm{HT}_{2}$ receptors to activate a calcium influx responsible for mitochondrial calcium increase ultimately leading to a mitochondrial $\mathrm{O}_{2} \bullet$ production.

In the present study, we first confirmed that 5 -HT produces $\mathrm{O}_{2} \bullet$ by means of: (i) EPR recordings and, (ii) measurement of $\mathrm{ONOO}^{-}$which, indirectly, quantifies $\mathrm{O}_{2} \bullet$. Interestingly, the production of $\mathrm{ONOO}^{-}$was consistent with our previous study, in which we demonstrated that $\mathrm{O}_{2} \bullet$ negatively controls endothelial-induced relaxation by reducing cGMP production, likely due to scavenging of the endothelial NO (Billaud et al., 2009).

The present data demonstrated that 5-HT-increased $\mathrm{O}_{2} \bullet$ levels is sensitive to inhibition of $5-\mathrm{HT}_{2}$ receptors with ketanserin, to extracellular calcium removal and to inhibition of voltage-independent calcium channels with RHC-80267 and LOE-908 (Figures 2, 3). On the other hand, we previously demonstrated that the contraction to $5-\mathrm{HT}$ is (i) sensitive to the same blockers (ketanserin, calcium free solution, RHC-80267 and LOE 908) (Guibert et al., 2004; Rodat et al., 2007; RodatDespoix et al., 2008) and (ii) implicates $\mathrm{O}_{2} \bullet$ produced by $5-\mathrm{HT}$ (Billaud et al., 2009), thus confirming that 5-HT-induced $\mathrm{O}_{2} \bullet$ production seems to be involved in the contraction to $5-\mathrm{HT}$ under physiological conditions in rat IPA. Consistently, other groups have also demonstrated that the contraction to $5-\mathrm{HT}$ is dependent on stimulation of $5-\mathrm{HT}_{2 \mathrm{~A}}$ receptors and extracellular calcium in rat pulmonary artery (MacLean et al., 1996; Yuan et al., 1997).

The 5-HT concentration used in the present study is high, much higher than the 5-HT levels detected in physiological conditions (around $10 \mathrm{nM}$ ) (Kéreveur et al., 2000). However, $10 \mathrm{nM}$ is the plasma 5-HT levels and we do not really know what is the actual concentration at the site of the pulmonary arteries and, more specifically, at the site of the smooth muscle cells. Taking into account that 5-HT is also produced in the lung by pulmonary neuroendocrine cells, endothelial cells and neuroepithelial bodies distributed throughout the airways (see introduction), we can speculate that smooth muscle cells are in contact with a higher 5-HT concentration than the circulating 5-HT levels. Moreover, the ROS-dependent process, described here, is supposed to be involved in the contractile response to 5-HT in rat IPA (Billaud et al., 2009) and we previously showed that the maximal contraction to 5-HT was obtained for 
A

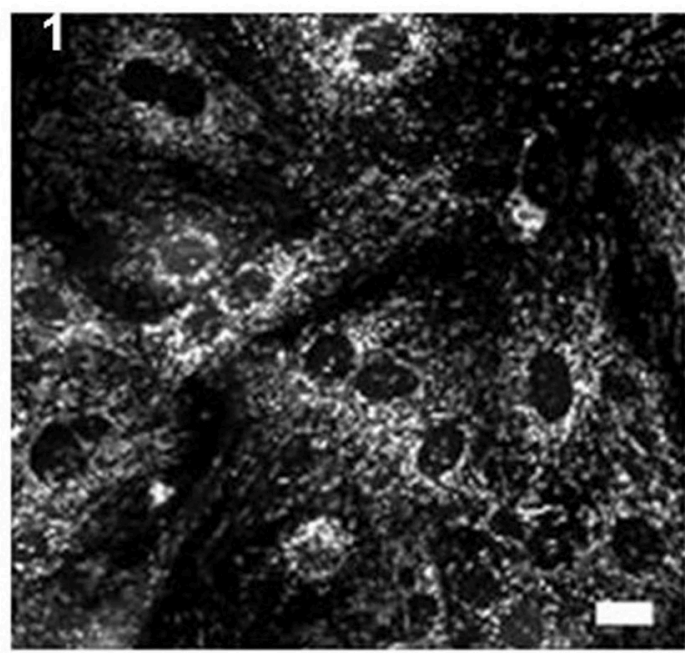

B

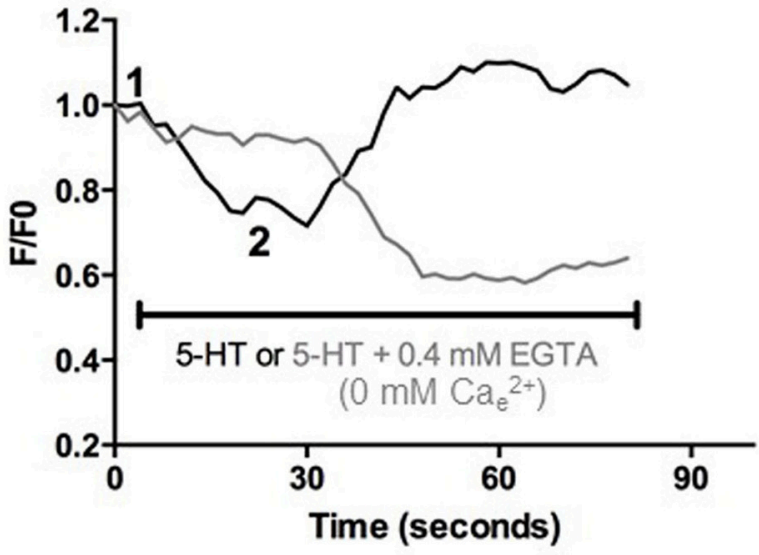

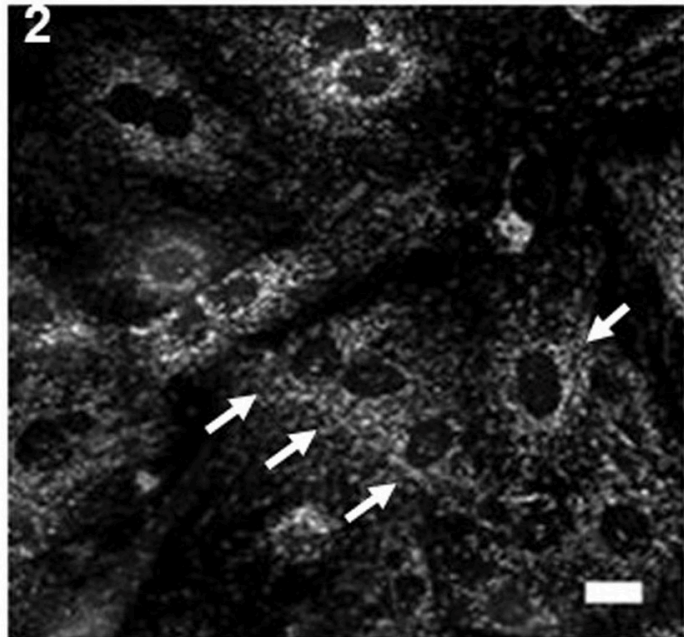

C

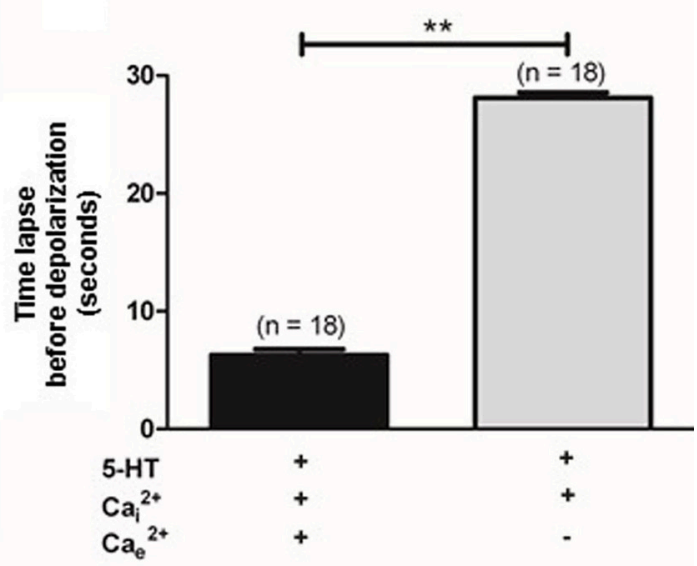

FIGURE 5 | Effect of 5-HT on mitochondrial membrane potential in PASMC. (A) Images 1 and 2 represent mitochondrial fluorescence before and after application of 5-HT $(100 \mu \mathrm{M})$. White arrows indicate cells with the highest decrease in fluorescence following 5-HT stimulation. Scale bars are $20 \mu \mathrm{m}$. (B) Typical traces of mitochondrial membrane potential in response to $5-\mathrm{HT}$ in the presence of $2 \mathrm{mM} \mathrm{Ca}_{\mathrm{e}}^{2+}$ (black line) or in the absence of $\mathrm{Ca}_{\mathrm{e}}^{2+}$ and the presence of $0.4 \mathrm{mM}$ EGTA (light gray line). One and two indicate the F/FO value for one cell from the corresponding images 1 and 2 shown in (A). F/Fo is the ratio of the fluorescence values F over the basal fluorescence FO (before application of the agonists). (C) Values of the time lapse between bath-application of 5-HT and the beginning of the mitochondrial membrane potential variation in the presence and in the absence of extracellular $\mathrm{Ca}^{2+}$ (black and light gray columns respectively). Data are expressed as mean \pm SEM. ${ }^{* \star}$ means a significant difference for $P<0.01 . n$ is the number of cells tested.

a concentration of $100 \mu \mathrm{M}$. For a 5-HT concentration of $1 \mu \mathrm{M}$, the amplitude of the contraction in rat IPA was of only about $10-20 \%$ of that induced by a high potassium solution $(80 \mathrm{mM})$ or about $30 \%$ of the maximal contraction (Guibert et al., 2004, 2005; Rodat et al., 2007; Rodat-Despoix et al., 2008; Billaud et al., 2009). Moreover, at lower concentration, the percentage of responding isolated cells to agonists is usually also lower, especially regarding calcium signal. Altogether, we thus decided to use a high concentration of 5-HT i.e., $100 \mu \mathrm{M}$.

Extensive studies have been performed on ROS production and on the sources involved in such production in the pulmonary circulation, especially in the case of hypoxic pulmonary vasoconstriction or pulmonary hypertension (Archer et al., 1993;
Leach et al., 2001; Rathore et al., 2008; Dromparis and Michelakis, 2013) but only one study addressed the issue of ROS production in response to vasocontractile agonist stimulation (Liu and Folz, 2004). Liu and Folz (2004) have shown the role of the NADPH oxidase in the production of $\mathrm{O}_{2} \bullet$ by 5 - HT in mice PA by using pharmacological and genetic approaches (apocynin and gp $91^{\text {phox }}$ knock-out mice, respectively) but they did not address the role of mitochondria. Other studies have shown, in bovine PASMC, that $5-\mathrm{HT}$ is up taken by the $5-\mathrm{HT}$ transporter and produces $\mathrm{O}_{2} \bullet$ which is then dismutated by SOD into $\mathrm{H}_{2} \mathrm{O}_{2}$ and participates to the 5-HT mitogenic activity (Lee et al., 1998, 2001). 5- $\mathrm{HT}_{1}$ and $5-\mathrm{HT}_{2}$ agonists fail to enhance $\mathrm{O}_{2}-$ release in bovine PASMC (Lee et al., 2001). In those studies, the role of $\mathrm{O}_{2} \bullet$ and/or $\mathrm{H}_{2} \mathrm{O}_{2}$ 

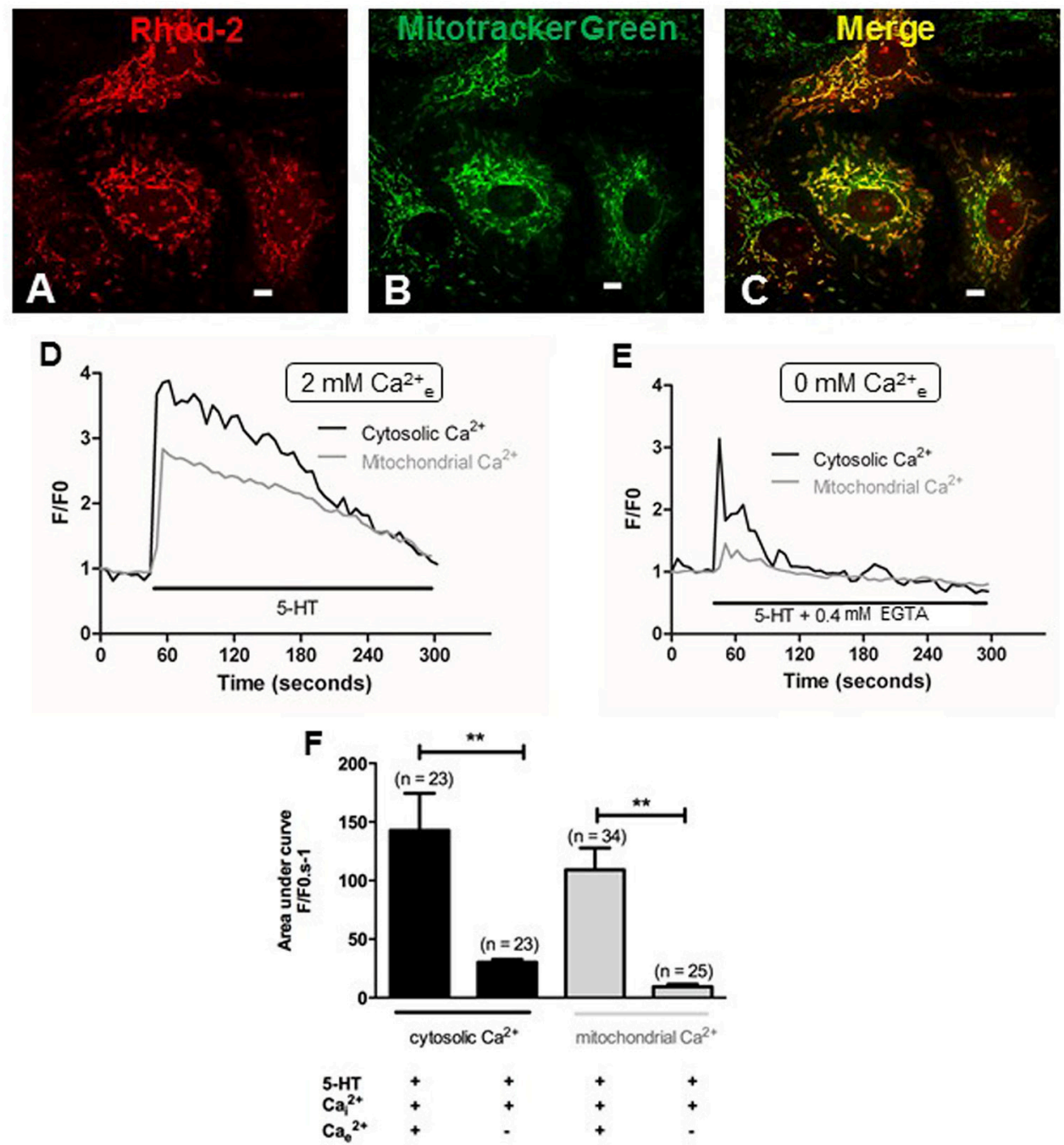

FIGURE 6 | Role of extracellular calcium in the cytosolic and mitochondrial calcium signals induced by 5-HT. (A,B) Show PASMC loaded with rhod-2

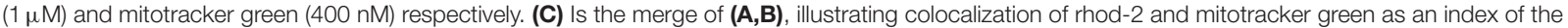
mitochondrial network in yellow. Scale bars are $20 \mu \mathrm{m}$. Typical traces of simultaneous recordings of cytosolic (black lines) and mitochondrial (light gray lines) $\mathrm{Ca}^{2+}$ levels in response to 5-HT $(100 \mu \mathrm{M})$ in PASMC are shown in the presence or in the absence of extracellular $\mathrm{Ca}^{2+}$ (D and $\mathbf{E}$ respectively). (F) Histograms of cytosolic and mitochondrial calcium variations (black and light gray columns respectively) induced by $5-\mathrm{HT}(100 \mu \mathrm{M})$ in the presence and in the absence of extracellular C $\mathrm{a}^{2+}$. $\mathrm{n}$ is the number of cells. ${ }^{\star *}$ means a significant difference for $P<0.01$

in the contraction to 5-HT has not been addressed. Interestingly, in our case, not only $5-\mathrm{HT}_{2}$ receptors activation increases $\mathrm{O}_{2} \bullet$ levels but citalopram, a 5-HT transporter inhibitor, does not affect 5 -HT-induced $\mathrm{O}_{2} \bullet$ production (Figure 2A) therefore we believe that we demonstrated the presence of another 5-HT signaling pathway associated to $\mathrm{O}_{2} \bullet$ production in rat IPA. Moreover, since the main role of the pulmonary circulation is to control blood/oxygen supply to the organs, hypoxic pulmonary vasoconstriction occurs in case of reduced alveolar oxygen, in order to redirect blood to more ventilated areas of the lung and ensure optimal gas exchange. Hypoxic sensor is still not clear however hypoxic pulmonary vasoconstriction is known to depend on mitochondrial-derived ROS production which reduces voltage-dependent potassium channels current and thus, increases intracellular calcium level in smooth muscle (Archer et al., 1993; Yuan et al., 1993; Leach et al., 2001; Dromparis and Michelakis, 2013; Freund-Michel et al., 2014). Acute hypoxia has also been shown to induce 5-HT secretion in pulmonary neuroendocrine cells (Cutz et al., 1993). Therefore, from our present results, we can speculate that the mitochondrial ROS involved in hypoxic pulmonary vasoconstriction may be produced by 5 -HT coming from pulmonary neuroendocrine cells.

Under pathophysiological conditions, $\mathrm{NO}$ reduction by $\mathrm{O}_{2} \bullet$ has already been observed in systems that overproduce ROS such as pulmonary and systemic hypertension (Brennan et al., 2003; Ago et al., 2011). However, so far, no study has demonstrated any role of mitochondrial $\mathrm{O}_{2} \bullet$ in the vascular 
A

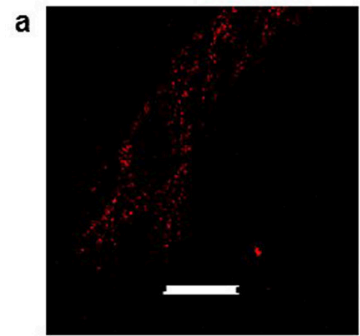

$2 \mathrm{Ca}^{2+}{ }_{\mathrm{e}}$

C

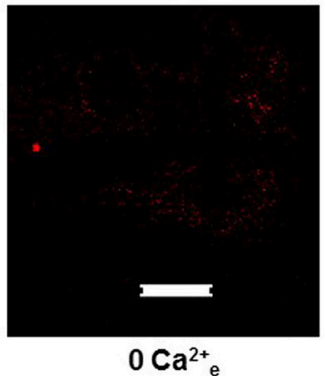

B
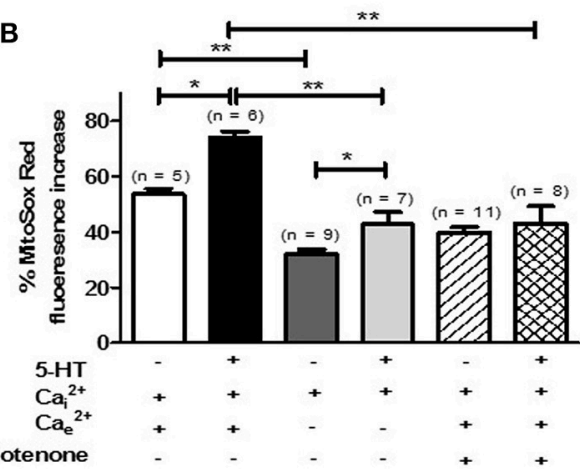

FIGURE 7 | 5 -HT-induced mitochondrial $\mathrm{O}_{2}-$ production is sensitive to extracellular calcium and rotenone in rat PASMC. (A) Shows images of mitochondrial mitosox fluorescence in untreated conditions (in presence or absence of extracellular calcium, $\mathbf{A a}$ and $\mathbf{A c}$ respectively) and following a 60 min incubation with $5-\mathrm{HT}(100 \mu \mathrm{M})$ in the presence or absence of extracellular calcium (Ab and $\mathbf{A d}$ respectively). Scale bar is $20 \mu \mathrm{m}$ for all images. (B) Means \pm SEM of the percent change in mitosox fluorescence after $60 \mathrm{~min}$ in untreated conditions in the presence of extracellular calcium or not (white and dark gray columns respectively), following 60 min of 5-HT (100 $\mu \mathrm{M})$ incubation in the presence of extracellular calcium or not (black and light gray columns respectively), in unstimulated conditions with rotenone (100 nM) (hatched column) and finally following a $60 \mathrm{~min}$ incubation with $5-\mathrm{HT}$, rotenone and both intra and extracellular calcium (double hatched column). $\mathrm{n}$ is the number of cells tested. * and ${ }^{* *}$ indicate a significant difference for $P<0.05$ and $P<0.01$ respectively.

responses to 5-HT or any other vasoconstrictor in physiological conditions. We have several lines of evidence arguing in favor of a role of mitochondria in response to 5-HT in general and, more specifically, in the production of $\mathrm{O}_{2} \bullet$ by $5-\mathrm{HT}$ under physiological conditions. First of all, 5-HT significantly decreased mitochondrial respiratory rate (Figure 4B) and significantly depolarized mitochondrial membrane (Figure 5). Moreover, $\mathrm{O}_{2} \bullet$ produced by 5 - $\mathrm{HT}$ is blocked by rotenone (Figure 4A) and 5-HT increases both the mitochondrial calcium concentration and $\mathrm{O}_{2} \bullet$ levels (Figures 6D,F, 7, respectively). Interestingly, in the absence of extracellular calcium, the increase in mitochondrial calcium concentration is almost suppressed (Figures 6E,F) and change in mitochondrial membrane potential is strongly delayed (Figures $\mathbf{5 B}, \mathbf{C}$ ) which is in accordance with data from the literature demonstrating that calcium influxes are buffered by mitochondria positioned close to the plasma membrane (McCarron et al., 2012). According to our results and findings from the literature, we thus suggest that extracellular calcium may be taken up by the mitochondria to depolarize mitochondrial membrane in order to produce $\mathrm{O}_{2} \bullet$.

In conclusion, 5-HT-induced production of $\mathrm{O}_{2}-$ is mediated by $5-\mathrm{HT}_{2}$ receptors and is dependent on the complex I of the METC. Extracellular calcium influx plays an important role in this process. Our study emphasized the presence of a mitochondrial calcium-dependent $\mathrm{O}_{2} \bullet$ production by 5 HT under physiological conditions thus revealing a novel unexpected physiological role for mitochondrial $\mathrm{O}_{2} \bullet$ in response to 5-HT. Since calcium and superoxide anion are involved in the pulmonary arterial contraction to 5-HT (Billaud et al., 2009), we thus described, in the present study, a potential alternative and novel mechanism for vascular tone regulation via the action of $\mathrm{O}_{2} \bullet$. Moreover, $\mathrm{O}_{2} \bullet$, 5- $\mathrm{HT}$ concentrations, intracellular calcium and vascular tone are known to be increased in pulmonary hypertension suggesting that such mitochondrial $\mathrm{O}_{2} \bullet$ produced by 5 -HT may also be of great importance in case of pulmonary hypertension. Such hypotheses need to be further investigated. 5-HT, ROS, and peroxynitrites are also involved in various vascular pathologies. Thus, such better understanding of 5-HT-induced ROS production could be of potential interest for new therapeutic strategies regarding pulmonary hypertension and vascular pathologies in general.

\section{AUTHOR CONTRIBUTIONS}

NG, MB, RR, MD, JG, BI, RM, J-PS, and CG conception and design of research; NG, CG, MB, MD, and JG performed experiments; NG and CG analyzed the data; NG, CG, MB, MD, and JG interpreted results of experiments; NG and CG prepared figures; NG, CG drafted manuscript; NG, MB, RR, MD, JG, BI, $\mathrm{RM}, \mathrm{J}-\mathrm{PS}$, and CG edited and revised manuscript and approved final version of manuscript.

\section{FUNDING}

This work was supported by Conseil Régional d'Aquitaine (20111302006) and INSERM. 


\section{REFERENCES}

Ago, T., Kuroda, J., Kamouchi, M., Sadoshima, J., and Kitazono, T. (2011). Pathophysiological roles of NADPH oxidase/nox family proteins in the vascular system. -Review and perspective. Circ. J. 75, 1791-1800. doi: 10.1253/circj.cj-11-0388

Archer, S. L., Huang, J., Henry, T., Peterson, D., and Weir, E. K. (1993). A redox-based $\mathrm{O} 2$ sensor in rat pulmonary vasculature. Circ. Res. 73, 1100-1112. doi: 10.1161/01.RES.73.6.1100

Billaud, M., Marthan, R., Savineau, J. P., and Guibert, C. (2009). Vascular smooth muscle modulates endothelial control of vasoreactivity via reactive oxygen species production through myoendothelial communications. PLoS ONE 4:e6432. doi: 10.1371/journal.pone.0006432

Brennan, L. A., Steinhorn, R. H., Wedgwood, S., Mata-Greenwood, E., Roark, E. A., Russell, J. A., et al. (2003). Increased superoxide generation is associated with pulmonary hypertension in fetal lambs: a role for NADPH oxidase. Circ. Res. 92, 683-691. doi: 10.1161/01.RES.0000063424.28903.BB

Cogolludo, A., Moreno, L., Lodi, F., Frazziano, G., Cobeño, L., Tamargo, J., et al. (2006). Serotonin inhibits voltage-gated $\mathrm{K}+$ currents in pulmonary artery smooth muscle cells: role of 5-HT2A receptors, caveolin-1, and KV1.5 channel internalization. Circ. Res. 98, 931-938. doi: 10.1161/01.RES. 0000216858.04599.e1

Cutz, E., Speirs, V., Yeger, H., Newman, C., Wang, D., and Perrin, D. G. (1993). Cell biology of pulmonary neuroepithelial bodies-validation of an in vitro model. I. Effects of hypoxia and $\mathrm{Ca} 2+$ ionophore on serotonin content and exocytosis of dense core vesicles. Anat Rec. 236, 41-52. doi: 10.1002/ar.10923 60109

Denton, R. M., Richards, D. A., and Chin, J. G. (1978). Calcium ions and the regulation of $\mathrm{NAD}+$-linked isocitrate dehydrogenase from the mitochondria of rat heart and other tissues. Biochem. J. 176, 899-906. doi: 10.1042/bj17 60899

Dromparis, P., and Michelakis, E. D. (2013). Mitochondria in vascular health and disease. Annu. Rev. Physiol. 75, 95-126. doi: 10.1146/annurevphysiol-030212-183804

Ducret, T., Guibert, C., Marthan, R., and Savineau, J. P. (2008). Serotonin-induced activation of TRPV4-like current in rat intrapulmonary arterial smooth muscle cells. Cell Calcium 43, 315-323. doi: 10.1016/j.ceca.2007.05.018

Freund-Michel, V., Khoyrattee, N., Savineau, J. P., Muller, B., and Guibert, C. (2014). Mitochondria: roles in pulmonary hypertension. Int. J. Biochem. Cell Biol. 55, 93-97. doi: 10.1016/j.biocel.2014.08.012

Gonzalez De La Fuente, P., Savineau, J. P., and Marthan, R. (1995). Control of pulmonary vascular smooth muscle tone by sarcoplasmic reticulum $\mathrm{Ca} 2+$ pump blockers: thapsigargin and cyclopiazonic acid. Pflugers Arch. 429, 617-624. doi: 10.1007/BF00373982

Guibert, C., Marthan, R., and Savineau, J. P. (1996). Angiotensin II-induced $\mathrm{Ca}(2+)$-oscillations in vascular myocytes from the rat pulmonary artery. Am. J. Physiol. 270, L637-L642.

Guibert, C., Marthan, R., and Savineau, J. P. (2004). 5-HT induces an arachidonic acid-sensitive calcium influx in rat small intrapulmonary artery. Am. J. Physiol. Lung Cell. Mol. Physiol. 286, L1228-L1236. doi: 10.1152/ajplung.002 65.2003

Guibert, C., Savineau, J. P., Crevel, H., Marthan, R., and Rousseau, E. (2005). Effect of short-term organoid culture on the pharmaco-mechanical properties of rat extra- and intrapulmonary arteries. Br. J. Pharmacol. 146, 692-701. doi: 10.1038/sj.bjp.0706379

Kéreveur, A., Callebert, J., Humbert, M., Hervé P., Simonneau, G., Launay, J. M., et al. (2000). High plasma serotonin levels in primary pulmonary hypertension. Effect of long-term epoprostenol (prostacyclin) therapy. Arterioscler. Thromb. Vasc. Biol. 20, 2233-2239. doi: 10.1161/01.ATV.20.10.2233

Lawrie, A., Spiekerkoetter, E., Martinez, E. C., Ambartsumian, N., Sheward, W. J., MacLean, M. R., et al. (2005). Interdependent serotonin transporter and receptor pathways regulate S100A4/Mts1, a gene associated with pulmonary vascular disease. Circ. Res. 97, 227-235. doi: 10.1161/01.RES.0000176025.57706.1e

Leach, R. M., Hill, H. M., Snetkov, V. A., Robertson, T. P., and Ward, J. P. (2001). Divergent roles of glycolysis and the mitochondrial electron transport chain in hypoxic pulmonary vasoconstriction of the rat: identity of the hypoxic sensor. J. Physiol. 536, 211-224. doi: 10.1111/j.1469-7793.2001. 00211.x

Lee, S. L., Simon, A. R., Wang, W. W., and Fanburg, B. L. (2001). $\mathrm{H}(2) \mathrm{O}(2)$ signals 5-HT-induced ERK MAP kinase activation and mitogenesis of smooth muscle cells. Am. J. Physiol. Lung Cell. Mol. Physiol. 281, L646-L652.

Lee, S. L., Wang, W. W., and Fanburg, B. L. (1998). Superoxide as an intermediate signal for serotonin-induced mitogenesis. Free Radic. Biol. Med. 24, 855-858. doi: 10.1016/S0891-5849(97)00359-6

Lee, S. L., Wang, W. W., Finlay, G. A., and Fanburg, B. L. (1999). Serotonin stimulates mitogen-activated protein kinase activity through the formation of superoxide anion. Am. J. Physiol. 277, L282-L291.

Liu, J. Q., and Folz, R. J. (2004). Extracellular superoxide enhances 5-HTinduced murine pulmonary artery vasoconstriction. Am. J. Physiol. Lung Cell. Mol. Physiol. 287, L111-L118. doi: 10.1152/ajplung.000 06.2004

Maclean, M. R., and Dempsie, Y. (2010). The serotonin hypothesis of pulmonary hypertension revisited. Adv. Exp. Med. Biol. 661, 309-322. doi: 10.1007/978-1-60761-500-2_20

MacLean, M. R., Sweeney, G., Baird, M., McCulloch, K. M., Houslay, M., and Morecroft, I. (1996). 5-Hydroxytryptamine receptors mediating vasoconstriction in pulmonary arteries from control and pulmonary hypertensive rats. Br. J. Pharmacol. 119, 917-930. doi: 10.1111/j.14765381.1996.tb15760.x

Martin, E., Dahan, D., Cardouat, G., Gillibert-Duplantier, J., Marthan, R., Savineau, J. P., et al. (2012). Involvement of TRPV1 and TRPV4 channels in migration of rat pulmonary arterial smooth muscle cells. Pflugers Arch. 464, 261-272. doi: $10.1007 / \mathrm{s} 00424-012-1136-5$

McCarron, J. G., Olson, M. L., and Chalmers, S. (2012). Mitochondrial regulation of cytosolic $\mathrm{Ca}(2)(+)$ signals in smooth muscle. Pflugers Arch. 464, 51-62. doi: 10.1007/s00424-012-1108-9

Morecroft, I., Loughlin, L., Nilsen, M., Colston, J., Dempsie, Y., Sheward, J., et al. (2005). Functional interactions between 5-hydroxytryptamine receptors and the serotonin transporter in pulmonary arteries. J. Pharmacol. Exp. Ther. 313, 539-548. doi: 10.1124/jpet.104.081182

Peña-Silva, R. A., Miller, J. D., Chu, Y., and Heistad, D. D. (2009) Serotonin produces monoamine oxidase-dependent oxidative stress in human heart valves. Am. J. Physiol. Heart Circ. Physiol. 297, H1354-H1360. doi: 10.1152/ajpheart.00570.2009

Perez-Vizcaino, F., Cogolludo, A., and Moreno, L. (2010). Reactive oxygen species signaling in pulmonary vascular smooth muscle. Respir. Physiol. Neurobiol. 174, 212-220. doi: 10.1016/j.resp.2010.08.009

Peskin, A. V., and Winterbourn, C. C. (2000). A microtiter plate assay for superoxide dismutase using a water-soluble tetrazolium salt (WST1). Clin. Chim. Acta 293, 157-166. doi: 10.1016/S0009-8981(99) 00246-6

Rathore, R., Zheng, Y. M., Niu, C. F., Liu, Q. H., Korde, A., Ho, Y. S., et al. (2008). Hypoxia activates NADPH oxidase to increase [ROS]i and $[\mathrm{Ca} 2+] \mathrm{i}$ through the mitochondrial ROS-PKCepsilon signaling axis in pulmonary artery smooth muscle cells. Free Radic. Biol. Med. 45, 1223-1231. doi: 10.1016/j.freeradbiomed.2008.06.012

Rodat, L., Savineau, J. P., Marthan, R., and Guibert, C. (2007). Effect of chronic hypoxia on voltage-independent calcium influx activated by 5-HT in rat intrapulmonary arteries. Pflugers Arch. 454, 41-51. doi: 10.1007/s00424-006-0178-y

Rodat-Despoix, L., Aires, V., Ducret, T., Marthan, R., Savineau, J. P., Rousseau, E., et al. (2009). Signalling pathways involved in the contractile response to 5-HT in the human pulmonary artery. Eur. Respir. J. 34, 1338-1347. doi: 10.1183/09031936.00143808

Rodat-Despoix, L., Crevel, H., Marthan, R., Savineau, J. P., and Guibert, C. (2008). Heterogeneity in 5-HT-induced contractile and proliferative responses in rat pulmonary arterial bed. J. Vasc. Res. 45, 181-192. doi: 10.1159/0001 11071

Rossignol, R., Gilkerson, R., Aggeler, R., Yamagata, K., Remington, S. J., and Capaldi, R. A. (2004). Energy substrate modulates mitochondrial structure and oxidative capacity in cancer cells. Cancer Res. 64, 985-993. doi: 10.1158/0008-5472.CAN-03-1101 
Yuan, X. J., Bright, R. T., Aldinger, A. M., and Rubin, L. J. (1997). Nitric oxide inhibits serotonin-induced calcium release in pulmonary artery smooth muscle cells. Am. J. Physiol. 272, L44-L50.

Yuan, X. J., Goldman, W. F., Tod, M. L., Rubin, L. J., and Blaustein, M. P. (1993). Hypoxia reduces potassium currents in cultured rat pulmonary but not mesenteric arterial myocytes. Am. J. Physiol. 264, L116-L123.

Yumnam, S., Hong, G. E., Raha, S., Saralamma, V. V., Lee, H. J., Lee, W. S., et al. (2016). Mitochondrial dysfunction and $\mathrm{Ca}(2+)$ overload contributes to hesperidin induced paraptosis in hepatoblastoma cells, HepG2. J. Cell. Physiol. 231, 1261-1268. doi: 10.1002/jcp.25222
Conflict of Interest Statement: The authors declare that the research was conducted in the absence of any commercial or financial relationships that could be construed as a potential conflict of interest.

Copyright (c) 2017 Genet, Billaud, Rossignol, Dubois, Gillibert-Duplantier, Isakson, Marthan, Savineau and Guibert. This is an open-access article distributed under the terms of the Creative Commons Attribution License (CC BY). The use, distribution or reproduction in other forums is permitted, provided the original author(s) or licensor are credited and that the original publication in this journal is cited, in accordance with accepted academic practice. No use, distribution or reproduction is permitted which does not comply with these terms. 